\title{
Clinical Perspective of Ectopic Pregnancy in a Tertiary Care Hospital in Karnataka, India
}

\author{
Dr. Surya Chandrika Bondada ${ }^{1}$, Dr. Malathi $\mathrm{T}^{2}$ \\ ${ }^{1}$ Post graduate, Kempegowda Institute of Medical Sciences, Bengaluru, Karnataka \\ ${ }^{2}$ Asst professor, Kempegowda Institute of Medical Sciences, Bengaluru, Karnataka
}

\begin{abstract}
Objectives: (1) To know the age group, parity and the risk factors with respect to ectopic pregnancy. (2) To know the clinical presentation of ectopic pregnancy. (3) To know the outcome of ectopic pregnancy. Materials and Methods: This is a retrospective study conducted in Kempegowda Institute of Medical Sciences and Research Centre, Bengaluru, India. Data was collected regarding 45 cases with ectopic pregnancy from December 2014 to January 2017. and parameters including age, parity, gestational age, risk factors, clinical presentation, need for transfusion of blood products, findings on ultra-sonogram and at surgery, duration of hospital stay and associated morbidity were assessed. Results: There was a significant association of ectopic pregnancy with risk factors, most common of which were a history of infertility and abortion(s). The classical triad of pain abdomen, amenorrhoea and vaginal bleeding were not seen in all cases. Pain was the most common presenting symptom seen in $93 \%$ of cases, followed by amenorrhoea in $84 \%$ of cases. Vaginal bleeding was seen in only $38 \%$ of cases. The most common signs encountered were pallor (82\%) and abdominal tenderness (77.7\%).Surgery by open method was the most common form of treatment. The commonest site of ectopic pregnancy was ampulla and there was haemoperitoneum in $93 \%$ of cases. Conclusion: Ectopic pregnancy can present in any form within a wide clinical spectrum and a high index if suspicion is mandatory with regard to history and clinical features. A preliminary investigation with a urine pregnancy test and an ultrasound is minimally invasive and appears to be adequate to diagnose a majority of ectopic pregnancies. Surgical intervention remains the mainstay of treatment and there appear to be minimal post-operative complications.
\end{abstract}

Keywords: Ectopic, Clinical, Presentation, Risk Factors, Outcome, Complications, Signs, Symptoms

\section{Background}

Throughout history, ectopic pregnancy was considered a very serious problem with high mortality rates. This perception has changed only recently with the increased ability to establish the diagnosis of ectopic pregnancy noninvasively in women with minimal clinical symptoms. Ectopic pregnancy has been defined as any intra or extrauterine pregnancy in which the fertilized ovum implants at an aberrant site which is inconducive to its growth and development(1).

Although there has been a massive increase in the incidence of ectopic pregnancy in recent years, the mortality of the disease has been static $(2,3)$. Therefore the main challenge in modern clinical practice is to identify and treat as early as possible those cases of ectopic pregnancy with the potential to cause serious morbidity and death, and at the same time to minimize interventions in those destined to be resolved without causing any harm.

\section{Objectives}

1. To know the age group, parity and the risk factors with respect to ectopic pregnancy.

2. To know the clinical presentation of ectopic pregnancy.

3 . To know the outcome of ectopic pregnancy.

\section{Materials And Methods}

A total of 45 patients admitted into Kempegowda Institute of Medical Sciences and Research Centre, Bengaluru, who were diagnosed with ectopic pregnancy were retrospectively analyzed in the period from December 2014 to January
2017. All women diagnosed with an ectopic pregnancy were included in the study and the cases where an ectopic gestation was not found on laparotomy/laparoscopy were excluded.The parameters assessed wereage, parity, gestational age, risk factors, clinical presentation, need for transfusion of blood products, findings on ultra-sonogram and at surgery, duration of hospital stay and morbidity associated with ectopic pregnancy.

\section{Results}

This study was conducted over a period from December 2014 to January 2017. and a total of 45 cases of ectopic pregnancy were diagnosed.Age at presentation ranged from 18-37 years; mean age was found to be 27.8 years.A majority of the cases were multigravidae $(73.4 \%)$ and $26.6 \%$ were primigravidae. A majority had associated risk factors but $22 \%$ of patients had no risk factors.

Table 1: Associated Risk Factors

(*Some patients had multiple risk factors.)

\begin{tabular}{|c|c|c|}
\hline Risk factors & Number of Cases & Percentage \\
\hline Abortion & 12 & $26.60 \%$ \\
\hline Infertility & 11 & $24.40 \%$ \\
\hline History of tubal surgery & 8 & $17.70 \%$ \\
\hline Previous LSCS & 8 & $17.70 \%$ \\
\hline History of using OCP's & 2 & $4.40 \%$ \\
\hline History of using IUCD & 2 & $4.40 \%$ \\
\hline Previous ectopic pregnancy & 2 & $4.40 \%$ \\
\hline
\end{tabular}

A majority of cases presented with pain abdomen(93.3\%) and amenorrhoea $(84.4 \%)$. Other presenting symptoms included abnormal vaginal bleeding (38\%), vomiting (31\%), giddiness/syncopal attacks $(17.7 \%)$ and burning micturition 


\section{International Journal of Science and Research (IJSR) \\ ISSN (Online): 2319-7064 \\ Index Copernicus Value (2015): 78.96 | Impact Factor (2015): 6.391}

$(13.3 \%)$. Uncommon symptoms were fever $(2.2 \%)$, loose stools $(6.6 \%)$ and constipation(4.4\%).On examination, the most common sign was abdominal tenderness(77.7\%) followed by adnexal tenderness and guarding.

Table 2: Presenting Signs

\begin{tabular}{|c|c|c|}
\hline & Number of Cases & Percentage \\
\hline Abdominal tenderness & 35 & $77.70 \%$ \\
\hline Adnexal tenderness & 13 & $28.80 \%$ \\
\hline Guarding & 12 & $26.60 \%$ \\
\hline Cervical movement tenderness & 7 & $15.50 \%$ \\
\hline Abdominal distension & 5 & $11.10 \%$ \\
\hline
\end{tabular}

At presentation, anaemia was found in $82 \%$ of patients and $8.8 \%$ patients had no clinical signs. Ultrasound and a urine pregnancy test were the investigative modalities that were used in the diagnosis for a majority of cases. Urinary pregnancy test was positive in $93.3 \%$ of patients. Ultrasound revealed a ruptured ectopic pregnancy in $48.8 \%$ of the cases, an unruptured ectopic pregnancy in $24.4 \%$ of cases and a heterogenous mass in $22.2 \%$ of cases.

In a majority of the cases, the ectopic pregnancies were found to be located in the ampullary segment (40\%), followed by the isthmus(22.2\%) andthe isthmo-ampullary junction (20\%).

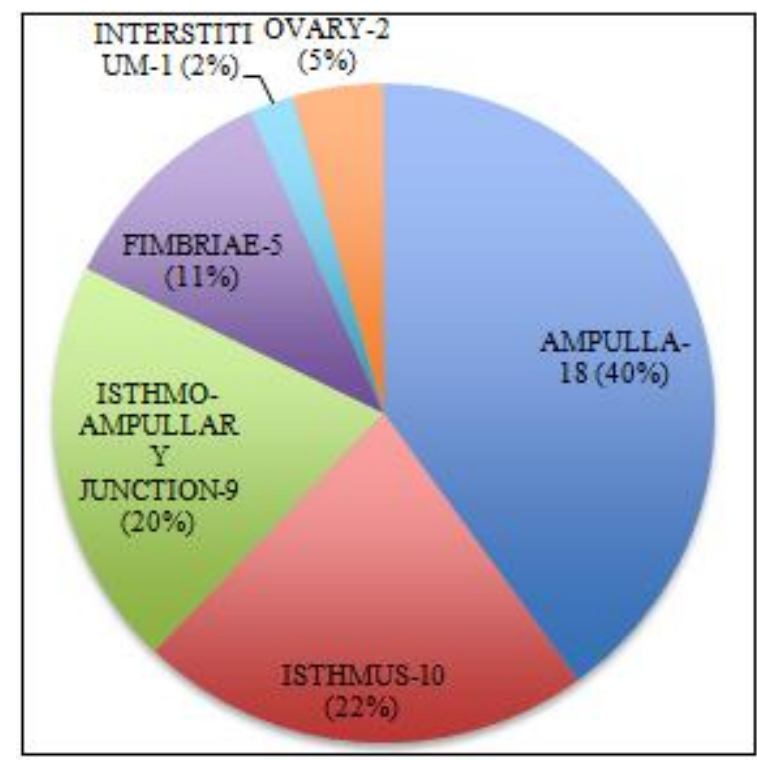

Chart 1: Sites of Ectopic Pregnancy Found IntraOperatively

Intra-operatively $58 \%(26)$ of cases were found to have a ruptured fallopian tube, $13.3 \%(6)$ were unruptured and $29 \%$ (13) were tubal abortions. There was haemoperitoneum in most cases (93.3\%), mean volume being $916.44 \mathrm{ml}$. Majority of cases were taken up for laparotomy.3 cases underwent laparoscopic surgery.

Table 3: Surgical Procedures Performed

\begin{tabular}{|c|c|c|}
\hline & Number of Cases & Percentage \\
\hline Unilateral salpingectomy & 24 & $53.30 \%$ \\
\hline $\begin{array}{c}\text { Unilateral salpingectomy with } \\
\text { contralateral tubectomy }\end{array}$ & 7 & $15.50 \%$ \\
\hline Bilateral salpingectomy & 6 & $13.30 \%$ \\
\hline Salpingo-oophorectomy & 5 & $11.10 \%$ \\
\hline
\end{tabular}

\begin{tabular}{|c|c|c|} 
Lap. unilateral salpingectomy & 2 & $4.40 \%$ \\
\hline $\begin{array}{c}\text { Lap. unilateral salpingectomy } \\
\text { with contralateral tubal occlusion }\end{array}$ & 1 & $2.20 \%$ \\
\hline
\end{tabular}

Lap: Laparaoscopic.

Of all cases, $69 \%$ needed intraoperative and/or postoperative blood transfusions. Morbidity included post-operative fever (15.5\%), need for ICU care $(13.3 \%)$, respiratory complications (pleural effusion, lung collapse) (4.4\%), carpo-pedal spasm $(2.2 \%)$, thrombocytopenia $(2.2 \%)$ and spurious diarrhea $(2.2 \%)$. There was no mortality in this study.Mean duration of stay was 7.2days.

\section{Discussion}

The incidence of ectopic pregnancy in the present study (1:133) was comparable to similar studies by Porwal Sanjay et al.(4)- 1:407 and R Jophy et al.(5)- 15:1000. The age of presentation was 18-37 years in the present study consistent with that recorded by and Khaleeque et al(6). A majority were multigravidae (74\%) and this is in agreement with the observation that ectopic pregnancy is more common in multigravidae (69\%)(7).

In the present study,there is a significant association of ectopic pregnancy with risk factors and the most common were a history of infertility (24.4\%) and abortion(s) (26.6\%). Arora et al.(8) and Gupta et al.(4) reported similar associations.A strong association was also found with previous tubal surgery $(17.7 \%)$ and other previous abdominal surgeries $(17.7 \%)$.

Pain was the most common presenting symptom (93\%) followed by amenorrhoea (84\%). Vaginal bleeding was seen in only $38 \%$ of cases.S Porwal et al reported a comparable incidence of pain abdomen $(87.5 \%)$, amenorrhoea $(90 \%)$ and vaginal bleeding $(67.5 \%)$ in their study(4). However, the classical symptoms of pain abdomen, amenorrhoea and vaginal bleeding were not seen in all cases. Uncommon presentations in this study included vomiting, burning micturition and syncopal attacks/dizziness.

Pallor was a significant finding and was seen in $82 \%$ of the cases. The second most common sign encountered was abdominal tenderness $(77.7 \%)$ and this incidence is comparable to $91 \%$ reported by Tay et al. and $83.9 \%$ by $\mathrm{R}$ Jophy et al(5) in their studies.

Table 4: Comparison Between Incidence Of Signs

\begin{tabular}{|c|c|c|c|}
\hline Presenting signs & $\begin{array}{c}\text { Tay et } \\
\text { al.(9) }\end{array}$ & $\begin{array}{c}\text { R Jophy et } \\
\text { al. (5) }\end{array}$ & $\begin{array}{c}\text { Present } \\
\text { study }\end{array}$ \\
\hline Abdominal tenderness & $91 \%$ & $83.90 \%$ & $77.70 \%$ \\
\hline Cervical movement tenderness & $54 \%$ & $55.90 \%$ & $15.50 \%$ \\
\hline Abdominal distension & - & $49.50 \%$ & $11.10 \%$ \\
\hline
\end{tabular}

In the present study, as most of the cases were suggestive of a ruptured ectopic pregnancy, surgery by open method was the mainstay of treatment, commonly in the form of unilateral salpingectomy $(54.54 \%)$. Surgery remains the mainstay of treatment in our country as medical management needs resources for close monitoring and follow up(10). 


\section{International Journal of Science and Research (IJSR) \\ ISSN (Online): 2319-7064 \\ Index Copernicus Value (2015): 78.96 | Impact Factor (2015): 6.391}

The most common site of ectopic pregnancy in the present study was ampulla and this finding is comparable with similar studies.

Table 5: Comparison Between Incidence Of Site Of Ectopic

\begin{tabular}{|c|c|c|c|}
\hline STUDY & Chow et al.(11) & Jophy et al.(5) & Present study \\
\hline Ampulla & $79.60 \%$ & $56.90 \%$ & $40 \%$ \\
\hline Isthmus & $12.30 \%$ & $39.78 \%$ & $22.20 \%$ \\
\hline Fimbria & $6.20 \%$ & - & $11.10 \%$ \\
\hline Interstitium & $1.90 \%$ & $1.07 \%$ & $2.20 \%$ \\
\hline Ovarian & - & $1.07 \%$ & $4.40 \%$ \\
\hline
\end{tabular}

Condition of the fallopian tube found intra-operatively was different in various studies. Rupture of tube in our study $(56.8 \%)$ was comparable to Latchaw et al.(12)who reported ruptured tube in $59 \%$ of cases. The incidence of haemoperitoneum was $93.9 \%$ (mean volume $916.44 \mathrm{ml}$ ) which is comparable to the observation of $86.4 \%$ by Rashmi et al.(13).

\section{Interpretation and Conclusion}

As evidenced by the prevalence of anaemia at presentation, finding of massive haemoperitoneum and need for transfusion of blood products in a majority of cases in this study, ectopic pregnancies have the potential to cause serious morbidity.

The early diagnosis of an ectopic pregnancy reduces the presentation to response time, which is crucial in determining the morbidity, mortality and long-term effects for the patient.

As an ectopic pregnancy can present in any form within a wide clinical spectrum, ranging from an asymptomatic patient to one in shock and in any age group, a high index if suspicion is mandatory with regard to history and clinical features. A preliminary investigation with a urine pregnancy test and an ultrasound is minimally invasive and appears to be adequate to diagnose a majority of ectopic pregnancies.

Surgical intervention remains the mainstay of treatment and there appear to be minimal post-operative complications.

\section{References}

[1] Jones HW, Rock JA. Te Linde's operative gynecology. Lippincott Williams \& Wilkins; 2015.

[2] into Maternal CE. Child Health. Why Mothers Die 1997-1999. The fifth report of the confidential enquiries into maternal deaths in the United Kingdom London: RCOG. 2001;137-138.

[3] Rajkhowa M, Glass MR, Rutherford AJ, Balen AH, Sharma V, Cuckle HS. Trends in the incidence of ectopic pregnancy in England and Wales from 1966 to 1996. BJOG: An International Journal of Obstetrics \& Gynaecology. 2000;107(3):369-374.

[4] Gupta R, Porwal S, Swarnkar M, Sharma N, Maheshwari P. Incidence, trends and risk factors for Ectopic Pregnancies in a tertiary care hospital of Rajasthan. Journal of Pharmaceutical and Biomedical Sciences (JPBMS). 2012;16(16):16.
[5] Jophy R, Thomas A, Mhaskar A. Ectopic pregnancy-5 year experience. J Obstet Gynecol Ind. 2002;52:55-8.

[6] Khaleeque F, Siddiqui RI, Jafarey SN. Ectopic pregnancies: a three year study. JPMA The Journal of the Pakistan Medical Association. 2001;51(7):240-243.

[7] Karki RC, Pradhan B, Duwa S. Annual analysis of ectopic pregnancy in tertiary care Hospital. Post Graduate Medical Journal of NAMS. 2011;11:5-8.

[8] Arora R, Rathore AM, Habeebullah S, Oumachigui A. Ectopic pregnancy--changing trends. J Indian Med Assoc. 1998 Feb;96(2):53-4, 57.

[9] Tay JI. Ectopic pregnancy (vol 320, pg 916, 2000). BRITISH MEDICAL JOURNAL. 2000;321(7258):424-424.

[10] Chatterjee S, Dey S, Chowdhury RG, Ganguli D, others. Ectopic Pregnancy In Previously Infertile Women Subsequent Pregnancy Outcome After Laparoscopic Management. Al Ameen J Med Sci. 2009;2(1):67-72.

[11] Chow WH, Daling JR, Cates W, Greenberg RS. Epidemiology of ectopic pregnancy. Epidemiol Rev. 1987;9:70-94.

[12] Latchaw G, Takacs P, Gaitan L, Geren S, Burzawa J. Risk factors associated with the rupture of tubal ectopic pregnancy. Gynecologic and obstetric investigation. 2005;60(3):177-180.

[13] Gaddagi RA, Chandrashekhar AP. A clinical study of ectopic pregnancy. J Clin Diagn Res. 2012;6(5):867. 